\title{
Comparison of Short-term Efficacy of Ranibizumab to Dexamethasone in the Treatment Naive Pseudophakic Diabetic Macular Edema: A Real-Life Study
}

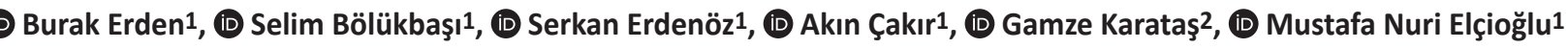 \\ 1 University of Health Sciences Turkey, istanbul Okmeydanı Training and Research Hospital, Clinic of Retina, istanbul, Turkey \\ 2Silivri State Hospital, Clinic of Eye, İstanbul, Turkey
}

\section{Abstract}

Objective: This study aimed to compare the short-term efficacy of dexamethasone (Dex) implant with those of three consecutive ranibizumab (Rzb) injections in the treatment-naive diabetic macular edema patients.

Methods: In this retrospective study, 30 eyes of 30 diabetic macular edema (DME) patients were enrolled in the intravitreal Rzb (IVR) group; 29 eyes of 29 patients were enrolled in the Dex implant (DI) group. The IVR group was treated with three consecutive monthly Rzb injections; the DI group was injected one single DI. Both groups underwent ophthalmological examinations and optical coherence tomography exams at baseline and 1st, $2^{\text {nd }}$, and 3rd month visits. Data were analyzed with SPSS 22.0, statistically.

Results: Mean age, duration of diabetes, baseline best-corrected visual acuity, and central macular thickness (CMT) of both arms were statistically indifferent. The intraocular pressure (IOP) changes were within and between groups insignificant. The comparison of visual gain at the final visit showed no difference $(p>0.05)$. The final CMT reduction in both groups was statistically insignificant (145 $\mu \mathrm{m}$ vs $110.5 \mu \mathrm{m}$ $\mathrm{p}>0.05)$. In the DI group, two eyes (7\%) had to be treated with topical anti-glaucomatous agents in the follow-up.

Conclusion: Both monthly Rzb injections and DI are equally effective in the initial treatment of DME. Although the treatment effect of the DI was seen earlier in the follow-up, the IOP elevations may be a clinical concern in some cases.

Keywords: Dexamethasone, diabetic macular edema, ranibizumab

\section{INTRODUCTION}

Diabetes is an emerging public health issue worldwide, and its complications are predicted to be one of the major problems of medical care in the upcoming years. Macular edema secondary to diabetic retinopathy is the leading cause of visual impairment at any stage of the disease. Ischemia-induced up-regulation of inflammatory mediators causes the breakdown of the bloodretinal barrier (BRB), leading to increased vascular permeability and macular edema. In the last decade, vascular endothelial growth factor (VEGF) is found to be the main factor of this pathogenesis. Thus, anti-VEGF treatment strategy-starting with the off-label usage of bevacizumab (1) improved itself to be superior to monotherapy with laser photocoagulation (2) or steroids in several studies (3). Following bevacizumab, ophthalmologically introduced anti-VEGF agents such as ranibizumab (Rzb) and aflibercept have proven them as effective in the treatment of diabetic macular edema (DME) $(4,5)$. Today, the first-line therapy for center-involving macular edema is anti-VEGF agents (6) that are competing with each other as it is reported recently in DRCR.net's comparative trial (7). However, corticosteroids-an old actor in the management of diabetic macular edema e.g., triamcinolone-returned with a slow-releasing biodegradable 
implant of dexamethasone (Dex) (Ozurdex; Allergan, Irvine, CA, USA) into our armamentarium (8). Although concerns about wellknown steroid-induced complications such as cataract formation or elevation of intraocular pressure (IOP) remain, clinicians consider this effective treatment modality as a second-line option reserved especially for anti-VEGF resistant DME cases rather than a first-line therapy.

In the literature, only a few reports are comparing anti-VEGF drugs with Dex implant (DI) head-to-head, based on real-life experience. In this present study, we aimed to compare the efficacy of a single DI to the intravitreal Rzb (IVR) loading phase in treatment-naive DME patients, to make a real-life analysis.

\section{METHODS}

This retrospective single-center study was conducted in the Retina Department of Okmeydanı Education and Research Hospital (OERH), University of Health Sciences, İstanbul. Ethical approval was approved by the Local Ethical Committee (48670771$514,10)$. The study has adhered to all aspects of the tenets of the Declaration of Helsinki. Informed consent was obtained from all the participants before each interventional procedure.

First of all, electronic and hardcopy records of ninety-eight treatment-naive DME patients-treated with either three consecutive IVR injections or a single DI between January 2017 and December 2018-were reviewed retrospectively. Our exclusion criteria were phakic lens status, the presence of coexisting ophthalmic pathologies such as glaucoma, retinal vein occlusions, the existence of vitreomacular interface disorders, or any prior treatment for DME such as any intravitreal injections or laser photocoagulation. Diffuse macular edema cases in the form of degenerative foveal thickening were also excluded to eliminate the effect of possible chronic foveal dysfunction. We included only the pseudophakic eyes into this study to subside the interference of cataract formation on visual results. According to our inclusion and exclusion criteria, fifty-nine eyes of 59 patients were enrolled finally into our study. 30 eyes of 30 patients were recruited into the Rzb (IVR) group and 29 eyes of 29 patients into the DI group.

While the IVR-group has undergone 3 consecutive intravitreal 0.5 mg Rzb injections (IVR) in a loading dose fashion, the DI-group was injected one single $0.7 \mathrm{mg}$ DI. All intravitreal injections were performed in an operating room; single-use intravitreal injection sets were used, 5\% povidone-iodine solution was applied at ocular surface minimum 5 minutes before injection, detailed informed consent forms were signed by each patient for any intervention, separately.
All patients underwent a baseline fluorescein angiography and spectral-domain optical coherence tomography (SD-OCT) (Cirrus; Zeiss, Germany) examination. Ophthalmic evaluation, including best-corrected visual acuity (BCVA) assessment in Snellen decimals, biomicroscopy, measurement of IOP by goldmann tonometry, funduscopy, and SD-OCT, were performed at baseline and $1^{\text {st }}, 2^{\text {nd }}$, and $3^{\text {rd }}$ month visits in the follow-up. We defined our primary outcome as changes in central macular thickness (CMT) and BCVA in both groups at the final visit.

\section{Statistical Analysis}

SPSS version 22.0 was preferred for statistical analysis. The variables were investigated using visual and analytical methods to determine whether or not they are normally distributed. The effect of the therapeutic agent on the change in BCVA, CMT, and IOP by time was investigated using repeated measures analysis of variance. The Greenhouse-Geisser correction was used when the sphericity assumption was violated. A multiple linear regression model was used to identify independent predictors of BCVA gain and CMT reduction. A $p$ value $<0.05$ was defined as statistical significant.

\section{RESULTS}

In this retrospective study, 30 eyes of 30 patients (IVR-group) and 29 eyes of 29 patients (DI- group) were studied. Both groups were similar in terms of sex, age, duration of diabetes, glycosylated $\mathrm{HbA}$, initial BCVA, CMT and IOP at baseline $(\mathrm{p}=0.821, \mathrm{p}=0.344$, $p=0.436, p=0.764, p=0.089, p=0.658$ and $p=0.460$, respectively). Table 1 summarizes the demographical and clinical features of both groups. The $p$ values represent the significance of the comparisons; both groups were found statistically indifferent in all pre-mentioned demographic and clinical features.

\section{Visual Outcomes}

At 1st month visit, the mean BCVA logarithm of the minimum angle of resolution increased in both study groups significantly [0.73 vs 0.57 (IVR); 0.94 vs 0.63 (DI); $p=0.02$ and $p<0.001$; respectively]. Although a significant increase in the mean BCVA compared to baseline continued in DI group at $2^{\text {nd }}$ month visit $(0.94$ vs $0.53 ; p<0.001)$, that upward trend did not reach a statistical significance in IVR group $(0.54 ; p=0.465)$ at this time point. At the final visit, while the mean BCVA in DI group remained stable and statistically significant $(0.54 ; \mathrm{p}=0.959$; 0.94 vs $0.63 p<0.001$ ), a slight increase in BCVA continued in IVR group $(0.46 ; p=0.051)$ still significant compared to baseline value ( 0.73 vs $0.46 ; p=0.01)$.

When the groups were compared with each other, the mean BCVA gain was found comparable through follow-up at every 
time point (Table 2; $p=0.080$; repeated measures analysis of variance). Figure 1 depicts the mean BCVA changes of both groups throughout the study period.

\section{Anatomical Outcome}

The mean CMT in both groups decreased from their baseline values significantly at the 1st month visit (from 448 to $316 \mu \mathrm{m}$ (DI), from 437 to $363 \mu \mathrm{m}$ (IVR); both $\mathrm{p}<0.001$; respectively). At 2nd month time point, CMT reduction continued in both groups,

Table 1. The demographical and clinical features of the both groups in study population

\begin{tabular}{|l|l|l|l|}
\hline & IVR & $\begin{array}{l}\text { DEX } \\
\text { implant }\end{array}$ & $\mathbf{p}$ \\
\hline Number of patients & 30 & 29 & - \\
\hline Gender, male (\%) & $14(46 \%)$ & $15(51 \%)$ & 0.821 \\
\hline Age, years \pm SD & $62.7 \pm 7.9$ & $64.7 \pm 7.8$ & 0.344 \\
\hline Duration of diabetes, years \pm SD & $12.2 \pm 2.3$ & $11.8 \pm 3.4$ & 0.436 \\
\hline Serum HbA1C (mg/dL) level & $7.9 \pm 1.3$ & $8.1 \pm 1.2$ & 0.764 \\
\hline Baseline BCVA (LogMAR) & $0.73 \pm 0.28$ & $0.94 \pm 0.56$ & 0.089 \\
\hline Baseline CMT ( $\mu$ m) & $437.6 \pm 86.5$ & $448 \pm 93.1$ & 0.658 \\
\hline Baseline IOP (mmHg) & $16.3 \pm 2.6$ & $15.8 \pm 2.9$ & 0.460 \\
\hline $\begin{array}{l}\text { BCVA: Best-corrected visual acuity, CMT: Central macular thickness, IOP: Intraocular, } \\
\text { pressure, SD: Standard deviation, LogMar: Logarithm of the minimum angle of } \\
\text { resolution, DEX: Dexamethasone, IVR: Intravitreal ranibizumab }\end{array}$ \\
\hline
\end{tabular}

Table 2. Comparison of both groups in BCVA, CMT and IOP changes in follow-up revealed a statistically significant difference in favor of DI group only in CMT reduction at $1^{\text {st }}$ and 2nd month visits*

\begin{tabular}{|c|c|c|c|}
\hline & IVR group & DI group & $\mathrm{p}$ value \\
\hline \multicolumn{4}{|c|}{ BCVA* (LogMAR) } \\
\hline Baseline & $0.73 \pm 0.28$ & $0.94 \pm 0.56$ & 0.089 \\
\hline 1 month & $0.57 \pm 0.35$ & $0.63 \pm 45$ & 0.600 \\
\hline 2 month & $0.54 \pm 0.46$ & $0.53 \pm 0.42$ & 0.703 \\
\hline 3 month & $0.46 \pm 0.35$ & $0.54 \pm 0.44$ & 0.449 \\
\hline \multicolumn{4}{|l|}{$\mathrm{CMT}^{* *}(\mu)$} \\
\hline Baseline & $437.6 \pm 86.5$ & $448 \pm 93.1$ & 0.658 \\
\hline 1 month & $362.5 \pm 80.6$ & $316.4 \pm 86$ & $0.038^{*}$ \\
\hline 2 month & $347.6 \pm 88$ & $301.1 \pm 67.6$ & $0.027^{*}$ \\
\hline 3 month & $320.6 \pm 70.2$ & $300.7 \pm 74.2$ & 0.297 \\
\hline \multicolumn{4}{|c|}{$10 \mathrm{P}^{* * *}(\mathrm{mmHg})$} \\
\hline Baseline & $16.3 \pm 2.6$ & $15.8 \pm 2.9$ & 0.460 \\
\hline $1^{\text {st }}$ month & $15.5 \pm 3.3$ & $17 \pm 4.5$ & 0.144 \\
\hline $2^{\text {nd }}$ month & $15.8 \pm 3.9$ & $18 \pm 5.4$ & 0.077 \\
\hline $3^{\text {rd }}$ month & $15.3 \pm 3.2$ & $16.6 \pm 4.4$ & 0.49 \\
\hline \multicolumn{4}{|c|}{$\begin{array}{l}\text { BCVA*: Best-corrected visual acuity, CMT**: Central macular thickness, IOP***: } \\
\text { Intraocular pressure, LogMar: Logarithm of the minimum angle of resolution, IVR: } \\
\text { Intravitreal ranibizumab, DI: Dexamethasone implant }\end{array}$} \\
\hline
\end{tabular}

although significant compared to baseline (448 to $301 \mu \mathrm{m}$ (DI); from 437 to $348 \mu \mathrm{m}$ (IVR); both $p<0.001$ ), these changes were statistically insignificant relative to previous visit (301 $\mu \mathrm{m}$ (DI), $348 \mu \mathrm{m}$ (IVR); $p=0.057, p=0.155$; respectively). At 3 rd month, the mean CMT value of DI group remained stable ( $301 \mu \mathrm{m}, \mathrm{p}=0.974)$, but it decreased in IVR group significantly $(321 \mu \mathrm{m}, \mathrm{p}<0.001)$.

The intergroup comparison aspect of CMT reduction revealed that patients in DI group had a more significant CMT reduction at 1 st and $2^{\text {nd }}$ month visits; ( $75 \mu \mathrm{m}$ vs $132 \mu \mathrm{m} ; 90 \mu \mathrm{m}$ vs 147 $\mu \mathrm{m}$; Table 2; $p=0.028$, repeated measures). However, at the final visit (month 3), the decrease of mean CMT value was statistically insignificant between groups (117 $\mu \mathrm{m}$ (IVR) vs $147 \mu \mathrm{m}$ (DI); $p>0.05)$. Although DI resulted in a faster improvement of CMT than IVR, the IVR group ended with a similar CMT reduction at the final visit. Figure 2 presents the mean CMT changes of both groups in the follow-up.

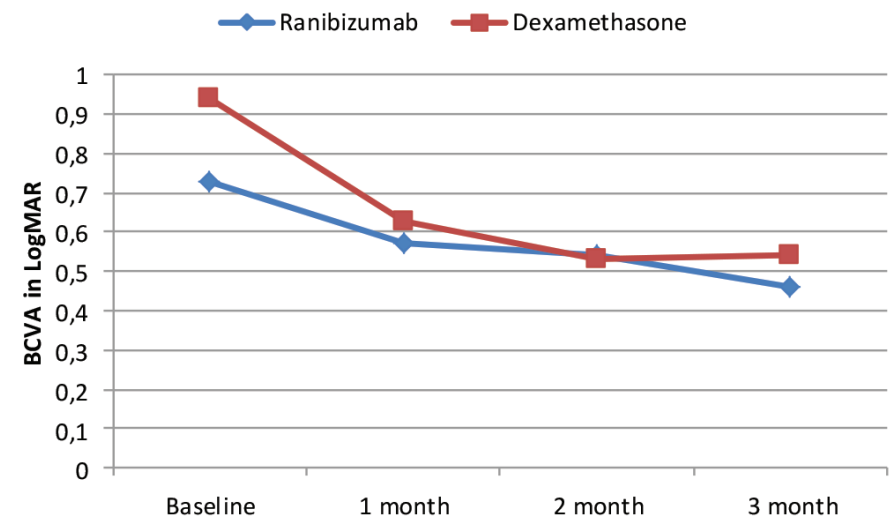

Figure 1. Comparison of BCVA through 3-month follow-ups revealed no significant difference between groups

BCVA: Best-corrected visual acuity, LogMAR: Logarithm of the minimum angle of resolution

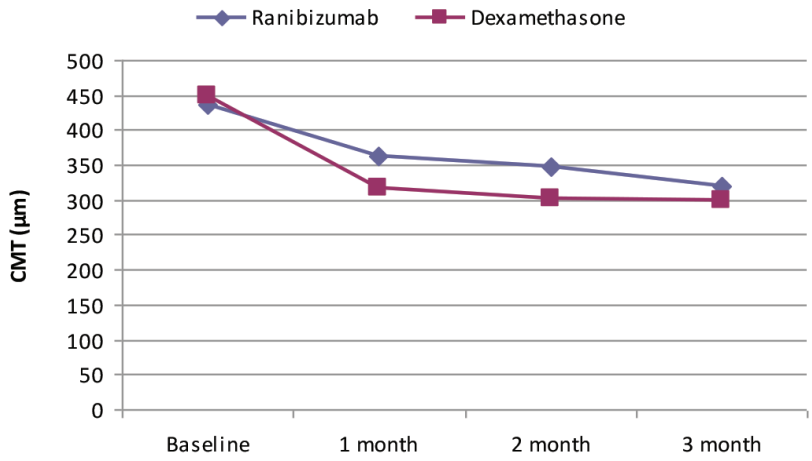

Figure 2. Regression of DME in both groups; the mean CMT value decreased in DI group at $1^{\text {st }}$ and $2^{\text {nd }}$ month visits significantly higher than in IVR group, but there was no statistical difference between groups at the $3^{\text {rd }}$ month visit

DME: Diabetic macular edema, CMT: Central macular thickness, DI: Dexamethasone implant, IVR: Intravitreal ranibizumab 


\section{IOP Changes}

The mean IOP increased in DI group at 1st month from its baseline value of $15.8 \pm 2.9 \mathrm{mmHg}$ to $17 \pm 4.5 \mathrm{mmHg}(p=0.311)$ and at $2^{\text {nd }}$ month to $18 \pm 5.4 \mathrm{mmHg}(\mathrm{p}=0.020)$. However, mean IOP was still found within normal ranges. At the $2^{\text {nd }}$ month visit, two eyes in the DI group had an IOP elevation higher than $5 \mathrm{mmHg}$, and these patients were started with topical anti-glaucomatous treatment in the follow-up. At 3 rd month, a decline of IOP was remarkable in DI group (16.6 $\pm 4.4 \mathrm{mmHg} ; \mathrm{p}=0.060)$. Conversely, the mean IOP in IVR group did not change significantly at any time point of the study period ( $p=0.654, p=0,373$; respectively).

The Comparison of IOP changes between groups revealed that-unlike IVR treatment DI leads to a significant rise in IOP, especially at months 1 and 2 ( $p=0.043$; repeated measures). Figure 3 demonstrates the mean IOP changes in three months follow-up.

\section{DISCUSSION}

The major cause of visual loss in the diabetic population is currently center-involving diabetic macular edema. Theoretically, regarding the role of chronic inflammation in the BRB disruption and DME pathogenesis, corticosteroids should be considered as first-line therapy (9). However, with the introduction of intravitreal anti-VEGF therapy, these agents dominated -with their safety and effective profile-the choice of treatment of this clinical problem in the last decade. Corticosteroids, however, came back late into our armamentarium in the form of a biodegradable sustained-release DI. In this current study, we aimed to compare a potent corticosteroid -Dex- with an antiVEGF agent, in a retrospective fashion in the aspect of efficacy.

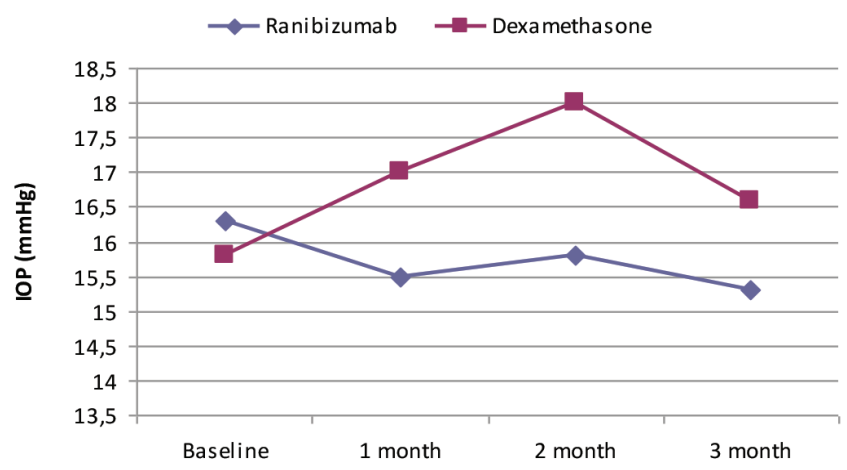

Figure 3. The mean IOP in DI group increased at $2^{\text {nd }}$ month visit significantly; a decline of IOP levels was observed after introducing topical anti-glaucomatous treatment in two cases of this group; on the other hand, the IOP remained stabile in IVR group throughout the study period DI: Dexamethasone implant, IVR: Intravitreal ranibizumab, IOP: Intraocular pressure
DI proved itself clearly as an effective agent in reducing DME in a combined treatment arm versus laser monotherapy in the PLACID trial (8). However, three-year results of the MEAD study-a randomized, sham-controlled pivotal trial - revealed also corticosteroids' well-known side-effects as cataract formation (67.9\%) and IOP elevation of $\geq 10 \mathrm{mmHg}(27.7 \%)$ in $0.7 \mathrm{mg}$ Dex arm, one patient even underwent incisional glaucoma surgery (10). These potential side effects of Dex limited its wide-use in DME cases, worldwide.

In persistent macular edema, however, inflammatory mediators other than VEGFs are suspected to be the leading cause of suboptimal response to anti-VEGF therapy and corticosteroids' broad anti-inflammatory effect may lead to promising results especially in anti-VEGF refractory DME cases. Thus, some recent studies emphasize this second-line therapy positioning of DI $(11,12)$

Regarding the way of different therapeutic mechanisms of antiVEGFs and steroids, there are only a few studies comparing these agents head-to-head in DME patients. In the first-year results of the BEVORDEX trial, a randomized, multicenter, prospective study DI administrations in every 16 weeks were compared to monthly bevacizumab injections (13). Although anatomical results were superior with fewer injections (2.7 vs 8.6) in the DI group (122 vs $187 \mu \mathrm{m}$ reduction in $\mathrm{CMT}$ ), functional results did not differ significantly, due to the impairing fact of cataract formation in the DI arm. The problem of cataract interference also raised in Callanan et al. (14) prospective, randomized, multi-centered study comparing Rzb with DI implant in a one-year followup. Sub-group analysis in this study revealed a better relative efficacy of DI compared with Rzb in baseline pseudophakic patients rather than in the total study population. Thus, despite our short follow-up, we enrolled only pseudophakic eyes into both our groups to subside the interaction of cataract formation on visual outcome.

In the comparative studies in diabetic population, one of the main issues is to find clinically equal groups for the enrollment. In this retrospective study, we carefully enrolled patients, evaluating systemic factors as gender, age, diabetic duration, HbA1c levels or ophthalmological findings as CMT or preoperative BVCA, aiming a statistically indifference in both arms. However, additional systemic or local factors may have affected our results. Thomas et al. (15), however, reported a contralateral eye-to-eye Rzb vs DI comparison in recalcitrant DME patients, eliminating the effects of systemic factors on their results. Similar to our study design, while Rzb group continued with monthly injections, DI group received one-single implant 
for 3-month follow-ups. They found in this refractory DME group that DI was superior both in anatomical and functional results over IVR therapy. In contrast to their findings, Aydın et al. (16) found IVR treatment anatomically and functionally superior to DI in chronic diabetic macular edema patients. In our treatmentnaive study group, however, we found IVR and DI statistically indifferent in the name of anatomical or functional results at the final visit.

Several studies in the literature reported promising results with DI in treatment of refractory DME patients $(17,18,12)$. In these preliminary case series reports, the "magical" therapeutic effect of DI started as early as $3^{\text {rd }}$ postoperative day (19) and reserved its efficacy up to $4^{\text {th }}$ month (12). These findings positioned DI naturally into a second-line therapy reserved for refractory DME cases. With this current study, however, we aimed to change this clinical approach, showing the fact that one-single DI reveals similar clinical results to 3 consecutive IVR injections in treatment-naive patients. As Wallick et al. (20) reported in their large-cohort retrospective study, patients with DME averaged more than 10 health care visits more than those with diabetes but no DME (25.5 vs $14.9 ; p<0.001)$ in a 4-year interval, DI may be a preferable first-line therapy alternative to reduce the treatment cost and visit burden of this population.

The well-addressed concern of IOP elevation remains a problematic issue in selecting the treatment choice. We found a slight but significant elevation of mean IOP value at the $2^{\text {nd }}$ month visit, deriving partially from the IOP elevation of higher than $5 \mathrm{mmHg}$ in two cases. In the follow-up, IOP values of these two eyes were under control with topical anti-glaucomatous medications, leading to a decline of mean IOP at the $3^{\text {rd }}$ month visit. Yılmaz et al. (21) reported in a large retrospective case series $(n=1110)$ that IOP was elevated in only 168 eyes $(15 \%)$, and topical therapy was started in 65 cases (5\%). They concluded DI proved itself relatively safe in means of IOP elevations. Actually, the glaucomatous effect of Dex is mainly encountered in the steroid-responder subgroup of the population and is reversible and transient, especially after a single implant, (21) DI may not be continued in such cases, as we did in these two patients in further follow-up.

In the aspect of anatomical results, the DI group revealed a characteristic response profile, with an early reduction of CMT, leading to a significant difference in favor of DI at $1^{\text {st }}$ and $2^{\text {nd }}$ month visits, similar to Callanan et al. (14) results. In IVR group, however, the mean CMT continued to decrease after the third IVR injection and caught up with the stabile DI group at the $3^{\text {rd }}$ month visit. This anatomical result at the final visit controversies to our general expectations that corticosteroids might be a more powerful treatment alternative. In visual gain, both groups revealed similar results through the study period.

\section{CONCLUSION}

The limitations of this current study are its lack of randomization due to its retrospective design, but we aimed to report our real-life experience in a comparative study. Although the short duration of our follow-up limits a reliable comparison of these both agents in long-term treatment, the comparable results of DI in naive DME patients support the idea of choosing this alternative for the first-line therapy in selected pseudophakic cases. We believe that this approach may have its benefits in reducing treatment burden and costs in the diabetic population.

\section{Ethics}

Ethics Committee Approval: This retrospective single-center study was conducted in the Retina Department of Okmeydanı Education and Research Hospital (OERH), University of Health Sciences, İstanbul. Ethical approval was approved by the Local Ethical Committee (48670771-514,10).

Informed Consent: Informed consent was obtained from all the participants before each interventional procedure.

Peer-review: Externally peer-reviewed.

\section{Authorship Contributions}

Surgical and Medical Practices: B.E., S.E., S.B., A.C., Concept: B.E., M.N.E., S.B., A.C., Design: B.E., M.N.E., S.B., S.E., G.K., Data Collection or Processing: B.E., G.K., A.C.., S.E., S.B., Analysis or Interpretation: B.E., S.E., A.C.., S.B., G.K., Literature Search: B.E., G.K., A.C.., S.E., M.N.E., Writing: B.E., S.E., A.C,., S.B., G.K.

Conflict of Interest: None of the authors have any conflict to disclose regarding this study.

Financial Disclosure: The authors did not get any financial support from any sources for this study.

\section{REFERENCES}

1. Haritoglou C, Kook D, Neubauer A, Wolf A, Priglinger S, Strauss R, et al. Intravitreal bevacizumab (Avastin) therapy for persistent diffuse diabetic macular edema. Retina 2006;26:999-1005.

2. Diabetic Retinopathy Clinical Research Network1; Writing Committee, Aiello LP, Beck RW, Bressler NM, Browning DJ, Chalam KV, Ferris FL 3rd, et al. Rationale for the diabetic retinopathy clinical research network treatment protocol for center-involved diabetic macular edema. Ophthalmology 2011;118:e5-14.

3. Elman MJ, Bressler NM, Qin H, Beck RW, Ferris FL 3rd, Friedman SM, et al; Diabetic Retinopathy Clinical Research Network. Expanded 2-year follow-up of ranibizumab plus prompt or deferred laser 
or triamcinolone plus prompt laser for diabetic macular edema Ophthalmology 2011;118:609-14.

4. Mitchell P1, Bressler N, Tolley K, Gallagher M, Petrillo J, Ferreira A, et al; RESTORE Study Group. Patient-reported visual function outcomes improve after ranibizumab treatment in patients with vision impairment due to diabetic macular edema: randomized clinical trial. JAMA Ophthalmol 2013;131:1339-47.

5. Korobelnik JF, Do DV, Schmidt-Erfurth U, Boyer DS, Holz FG, Heier JS, et al. Intravitreal aflibercept for diabetic macular edema. Ophthalmology 2014;121:2247-54.

6. Schmidt-Erfurth U1, Garcia-Arumi J, Bandello F, Berg K, Chakravarthy U, Gerendas BS, et al. Guidelines for the Management of Diabetic Macular Edema by the European Society of Retina Specialists (EURETINA). Ophthalmologica 2017;237:185-222.

7. Wells JA, Glassman AR, Ayala AR, Jampol LM, Bressler NM, Bressler SB, et al; Diabetic Retinopathy Clinical Research Network. Aflibercept, Bevacizumab, or Ranibizumab for Diabetic Macular Edema: Two-Year Results from a Comparative Effectiveness Randomized Clinical Trial. Ophthalmology 2016;123:1351-9.

8. Callanan DG, Gupta S, Boyer DS, Ciulla TA, Singer MA, Kuppermann BD, et al; Ozurdex PLACID Study Group. Dexametasone intravitreal implant in combination with laser photocoagulation for the treatment of diffuse diabetic macular edema. Ophthalmology 2013;120:1843-51.

9. Noma H, Mimura T,Yasuda K, Shimura M. Role of inflammation in diabetic macular edema. Ophthalmologica 2014;232:127-35.

10. Boyer DS, Yoon YH, Belfort R Jr, Bandello F, Maturi RK, Augustin AJ, et al; Ozurdex MEAD Study Group. Three-year, randomized, sham-controlled trial of dexametasone intravitreal implant in patients with diabetic macular edema. Ophthalmology 2014;121:1904-14.

11. Dutra Medeiros M, Postorino M, Navarro R, Garcia-Arumí J, Mateo C, Corcóstegui B. Dexamethasone intravitreal implant for treatment of patients with persistent diabetic macular edema. Ophthalmologica 2014;231:141-6.

12. Lazic R, Lukic M, Boras I, Draca N, Vlasic M, Gabric N, et al. Treatment of anti-vascular endothelial growth factor-resistant diabetic macular edema with dexamethasone intravitreal implant. Retina 2014;34:719-24.
13. Gillies MC, Lim LL, Campain A, Quin GJ, Salem W, Li J, et al; A randomized clinical trial of intravitreal bevacizumab versus intravitreal dexamethasone for diabetic macular edema: the BEVORDEX study. Ophthalmology 2014;121:2473-81.

14. Callanan DG, Loewenstein A, Patel SS, Massin P, Corcóstegui B, Li XY, et al; A multicenter, 12-month randomized study comparing dexamethasone intravitreal implant with ranibizumab in patients with diabetic macular edema. Graefes Arch Clin Exp Ophthalmol 2017;255:463-73.

15. Thomas BJ, Yonekawa Y, Wolfe JD, Hassan TS. Contralateral eye-toeye comparison of intravitreal ranibizumab and a sustained-release dexamethasone intravitreal implant in recalcitrant diabetic macular edema. Clin Ophthalmol 2016;10:1679-84.

16. Aydın E, Karaboğa NA, Eğrilmez ED, Kazancı L. Tip 2 diyabetik hastalarda kronik diyabetik makula ödem tedavisinde deksametazon implant ve intravitreal ranibizumabın etkinliğinin karșılaștırılması. Retina-Vitreus 2019;28:25-31.

17. Zucchiatti I, Lattanzio R, Querques G, Querques L, Del Turco C, Cascavilla $\mathrm{ML}$, et al. Intravitreal dexamethasone implant in patients with persistent diabetic macular edema. Ophthalmologica 2012;228:117-22.

18. Pacella E, Vestri AR, Muscella R, Carbotti MR, Castellucci M, Coi L, et al. Preliminary results of an intravitreal dexamethasone implant $\left(\right.$ Ozurdex $\left.^{\circledR}\right)$ in patients with persistent diabetic macular edema. Clin Ophthalmol 2013;7:1423-8.

19. Malclès A, Dot C, Voirin N, Vié AL, Agard É, Bellocq D, et al. Safety of Intravitreal Dexamethasone Implant (Ozurdex): The SAFODEX study. Incidence and Risk Factors of Ocular Hypertension. Retina 2017;37:13529 .

20. Wallick CJ, Hansen RN, Campbell J, Kiss S, Kowalski JW, Sullivan SD. Comorbidity and Health Care Resource Use Among Commercially Insured Non-Elderly Patients With Diabetic Macular Edema. Ophthalmic Surg Lasers Imaging Retina 2015;46:744-51.

21. Yılmaz I, Saraçoğlu B, Ahmet S, Baz Ö, Özkaya A, Tașkapılı M. Tek deksametazon implant enjeksiyonu sonrası göz içi basıncı değişiklikleri: Gerçek hayat klinik çalışması, 1110 vaka serisi. Retina-Vitreus 2017;26:99-104. 